\title{
Establishment and characterization of a novel, spontaneously immortalized retinoblastoma cell line with adherent growth
}

\author{
JEONG HUN KIM ${ }^{1}$, JIN HYOUNG KIM ${ }^{2}$, YOUNG SUK YU ${ }^{1,5}$, \\ DONG HUN KIM ${ }^{3}$, CHONG JAI KIM ${ }^{4}$ and KYU-WON KIM ${ }^{2}$ \\ ${ }^{1}$ Department of Ophthalmology, Seoul National University College of Medicine and Seoul Artificial Eye Center, \\ Clinical Research Institute, Seoul National University Hospital; ${ }^{2}$ NeuroVascular Coordination Research Center, \\ College of Pharmacy and Research Institute of Pharmaceutical Sciences, Seoul National University, Seoul; \\ ${ }^{3}$ Department of Radiology, College of Medicine, Chosun University, Gwangju; ${ }^{4}$ Department of Pathology, \\ Seoul National University College of Medicine, Seoul, Korea
}

Received April 10, 2007; Accepted June 11, 2007

\begin{abstract}
Retinoblastoma is the most common intraocular cancer of childhood, however, only a few cultured retinoblastoma cell lines are available to date. In the present study, we established a new human retinoblastoma cell line with adherent growth, named SNUOT-Rb1. The SNUOT-Rb1 cell line was established from an eye with retinoblastoma, which was enucleated from a 3-year-old Korean child. SNUOT-Rb1 has morphological and biochemical characteristics common to previous human retinoblastoma cell line, Y79: morphological features of fibroblast- or ganglion-like cells, and biochemical features of expression of glial fibrillary acidic protein and neuron-specific enolase. However, compared to Y79, SNUOT$\mathrm{Rb} 1$ has a unique characteristic of growing in adherence, and the doubling time of SNUOT-Rb1 is shorter than Y79 in adherent or floating growth. In analysis of the tumorigenic potential of SNUOT-Rb1 in nude mice, orthotopic implantation of SNUOT-Rb1 mimics the pattern of local growth of retinoblastoma. In comparative genomic hybridization analysis, we found that SNUOT-Rb1 has significant chromosomal imbalances on chromosome 3, 9, 10, 11, 14, 16, 17, and 22. Therefore, SNUOT-Rb1 could be useful in studying the biological and genetic characteristics of retinoblastoma for insights into the heredity and genetics of childhood cancer.
\end{abstract}

\section{Introduction}

Retinoblastoma is the most common intraocular cancer of childhood with an incidence of approximately 1 in 15,000 to 20,000 births, which represents the prototypic model for

Correspondence to: Dr Young Suk Yu, Department of Ophthalmology, College of Medicine, Seoul National University, Seoul 110-744, Korea

E-mail: ysyu@snu.ac.kr

Key words: retinoblastoma cell line, adherent growth, orthotopic implantation, comparative genomic hybridization inherited cancers (1-3). $R B 1$ was the first tumor-suppressor gene to be identified, leading to the discovery of a whole new class of antioncogenes and greatly contributing to advances in the management of solid tumors in children.

Mutations in both alleles of the $R B 1$ gene, a tumor suppressor in $13 \mathrm{q} 14$, are causative of the development of retinoblastoma (4). Additional mutations, however, may be prerequisite for $\mathrm{Rbl} / \mathrm{/}$ - cells to progress to tumorigenesis (5). Also, a study of $R b 1$ knock-out mice showed that loss of both alleles of the $R b 1$ gene is insufficient for tumor formation (6). In $60 \%$ of all retinoblastoma, the tumor is restricted to one eye and the $R b l$ gene mutations are somatic and nonhereditary, whereas $40 \%$ are germ-line and hereditary (7).

The study of the molecular mechanisms of oncogenesis in retinoblastoma has led to an understanding of the role that tumor suppressors, oncogenes, and deoxyribonucleic acid (DNA) repair genes play in development of the disease. For research on cancer biology, tumor cell culture is an effective tool to identify the cell of origin as well as subsequent genetic defects that contribute to pathogenesis. The majority of in vitro and in vivo investigations for retinoblastoma have been carried out using human retinoblastoma cell lines such as Y79 (8) and WERI-Rb1 (9), which both spontaneously grow in suspension. Here we report the establishment and characterization of a new, spontaneously immortalized human retinoblastoma cell line, designated SNUOT-Rb1. SNUOT-Rb1, naturally growing in attachment, demonstrates some features common to, or different from other retinoblastoma cell lines. This newly established cell line, SNUOT-Rb1, can be an in vitro model to provide the means for the study of characterizing properties of human retinoblastoma.

\section{Materials and methods}

Establishment of the tumor cell line. The sample was provided with informed consent, institutional review board approval was obtained, and the tenets of the Declaration of Helsinki were followed. Primary tumor material was obtained from eyes and immediately transferred into RPMI-1640 without FBS. The tissue was minced, washed with PBS to remove 
any residual blood. The washed cells were then cultured in RPMI-1640 containing penicillin-streptomycin (10 ml/1, Gibco BRL, Invitrogen, Carlsbad, CA) and $10 \%$ fetal bovine serum (Gibco BRL) at $37^{\circ} \mathrm{C}$ in $5 \% \mathrm{CO}_{2}$ in a humidified incubator. The culture medium was changed every three days. Cultured tumor cells were observed daily under a phase-contrast microscope.

Induction differentiation of SNUOT-Rb1. All-trans retinoic acid (RA; Sigma-Aldrich, St. Louis, MO) was dissolved in dimethylsulphoxide (DMSO; Sigma) as a stock solution at $10 \mathrm{mM}$. After 2 days in culture, the medium was replaced with fresh medium containing $10 \mu \mathrm{M}$ RA or $0.1 \%$ DMSO (negative control). Cultures were examined over 10 days. Culture medium was changed every three days.

Reverse transcription-polymerase chain reaction (RT-PCR). Total RNA was prepared from cells using TRIzol reagent, according to the manufacturer's protocol (Invitrogen, New Zealand). RNA was dissolved in diethyl pytocarbonate (DEPC) $-\mathrm{H}_{2} \mathrm{O}$ and first-strand cDNA synthesis was performed using SuperScript ${ }^{\mathrm{TM}}$ II RNAse H-reverse transcriptase (Invitrogen) and an oligo-dT primer. The cDNA was subjected to 30 cycles of amplification using the primers; RAR $\alpha$ forward 5'-CCTCTACCCCGCATCTACAA-3' and reverse 5'-TTGA GGAGGGTGATCTGGTC-3', GAPDH forward 5'-AAGGT CATCCCTGAGCTGAA-3' and reverse 5'-CCCCTCTTCA AGGGGTCTAC-3' at $95^{\circ} \mathrm{C}$ for $1 \mathrm{~min}, 58^{\circ} \mathrm{C}$ for $1 \mathrm{~min}$, and $72^{\circ} \mathrm{C}$ for $1 \mathrm{~min}$. The PCR products were analyzed on $1 \%$ agarose gels stained with ethidium bromide.

Immunocytochemistry of Y79 cells and SNUOT-Rb1. Cells were grown as attachment cultures, seeded at a concentration of $1 \times 10^{5}$ cells $/ \mathrm{ml}$, on coverslips (Deckglaser, Germany) precoated with $0.1 \mathrm{mg} / \mathrm{ml}$ poly-D-lysine (Sigma) and incubated at $37^{\circ} \mathrm{C}$ for one day. Coverslips were blocked for $30 \mathrm{~min}$ with DakoCytomation Protein Block (DakoCytomation, USA) at room temperature, and then incubated with anti-human glial fibrillary acidic protein (GFAP) (1:100, DakoCytomation) or anti-human neuron-specific enolase (NSE) (1:50, DakoCytomation) antibodies at $-4^{\circ} \mathrm{C}$ overnight. For negative control, mouse IgG was used as the primary antibody. Then, cells were incubated at room temperature for $60 \mathrm{~min}$ with polyclonal goat anti-mouse immunoglobin (1:5,000, DakoCytomation). Finally, samples were detected with an AEC substrate kit (Zymed Lab. Inc. South San Francisco, USA).

Rate of cell growth study. The growth curve of the tumor cells was obtained by seeding the cells at $2 \times 10^{4}$ cells/well in a 12-well plate (Nunc, Roskilde, Denmark). The media were changed every two days. The number of cells per well was counted every day for 8 days after incubation at $37^{\circ} \mathrm{C}$ in $5 \%$ $\mathrm{CO}_{2}$ of a humidified incubator, based on triplicate wells per time point. The average number of viable cells was counted on a hemacytochamber in the presence of trypan blue dye. The doubling time of the cell population was calculated from the exponential growth phase of the growth curve.

Induction of tumor formation. To determine the tumorigenicity of SNUOT-Rb1 cells in vivo, $1 \times 10^{7}$ cells were suspended in
PBS and injected into the intravitreal cavity of BALB/c-nude mice. The SNUOT-Rb1-injected animals were checked for tumors over 4 weeks.

Microarray comparative genomic hybridization (CGH) analysis. Microarray CGH was performed using the GenoSensor Array 300 system, following the manufacturer's instructions (ABBOT-Vysis, Downers Grove, IL, USA). Each array contains 861 spots, representing 287 chromosomal regions that are commonly altered in human cancer. Briefly, $100 \mathrm{ng}$ of genomic DNA were labeled by a random primer reaction during $2 \mathrm{~h}$. Tumor DNA was labeled with Cy3 and the normal male reference DNA with Cy5. After the labeling reaction, the probes were digested with DNAse at $15^{\circ} \mathrm{C}$ for $1 \mathrm{~h}$, followed by two ethanol-purifications; finally the probe size was checked by gel electrophoresis. The hybridization mixture consisted of $2.5 \mu \mathrm{l}$ of each of the differentially labeled DNAs plus $25 \mu 1$ of hybridization buffer provided in the kit. This mixture was denatured at $80^{\circ} \mathrm{C}$ for $10 \mathrm{~min}$, followed by incubation at $37^{\circ} \mathrm{C}$ for $1 \mathrm{~h}$. Of this probe, $5 \mu \mathrm{l}$ was applied onto the spotted area of the array under a coverslip and hybridized in a humid chamber containing $50 \%$ formamide (FA)/2X SSC at $37^{\circ} \mathrm{C}$ for $72 \mathrm{~h}$. After hybridization, the arrays were washed 3 times in $50 \% \mathrm{FA} / 2 \mathrm{X} \mathrm{SSC}$ at $40^{\circ} \mathrm{C}$ for $10 \mathrm{~min} /$ wash, followed by four 5-min washes in $1 \mathrm{X} \mathrm{SSC}$ at room temperature. Finally, the arrays were briefly rinsed in distilled water, mounted and counterstained in the dark for 45 min with DAPI (4,6-diamino2-phenylindole).

Array analysis was performed immediately after counterstaining using the GenoSensor scanner and software. Since each spot in the array is present in triplicates, the median of the three spots of each probe in the array was calculated and its $\log 2$ transformed value was used for further analysis. A fluorescence ratio $>1.25(\log 2,0.32)$ was considered as a DNA gain, while DNA losses were scored when the ratio was $<0.75(\log 2,-0.41)$.

\section{Results}

Pathological features of the primary tumor and isolation of SNUOT-Rb1. An eye with retinoblastoma was enucleated from a 3-year-old Korean child. As shown in hematoxylin/eosin staining, the endophytic retinoblastoma occupied over half of the vitreous cavity with some intravitreal seedings, but without invasion to the choroid or optic nerve head. The retina was shown to be extensively infiltrated by small, round cells with scanty cytoplasm and hyperchromatic nuclei. Viable tumor cells with mitotic features around blood vessels were surrounded by large area of necrosis, which were dispersed all over the tumor. There were small Flexner-Wintersteiner rosettes. (Fig. 1A) SNUOT-Rb1 was generated in vitro directly from cells isolated from fresh sterile retinoblastoma. SNUOT-Rb1 showed the microscopic features of fibroblastor ganglion-like cells with adherent growth in a monolayer (Fig. 1B). The adherent growth is a unique characteristic of SNUOT-Rb1, different from other retinoblastoma cell lines such as Y79, or WERI-Rb1. RA triggered the differentiation of SNUOT-Rb1 to extend neuritis (Fig. 1B).

Morphological and growth characteristics of SNUOT-Rb1. As previously reported (10), RA upregulated retinoic acid 
A

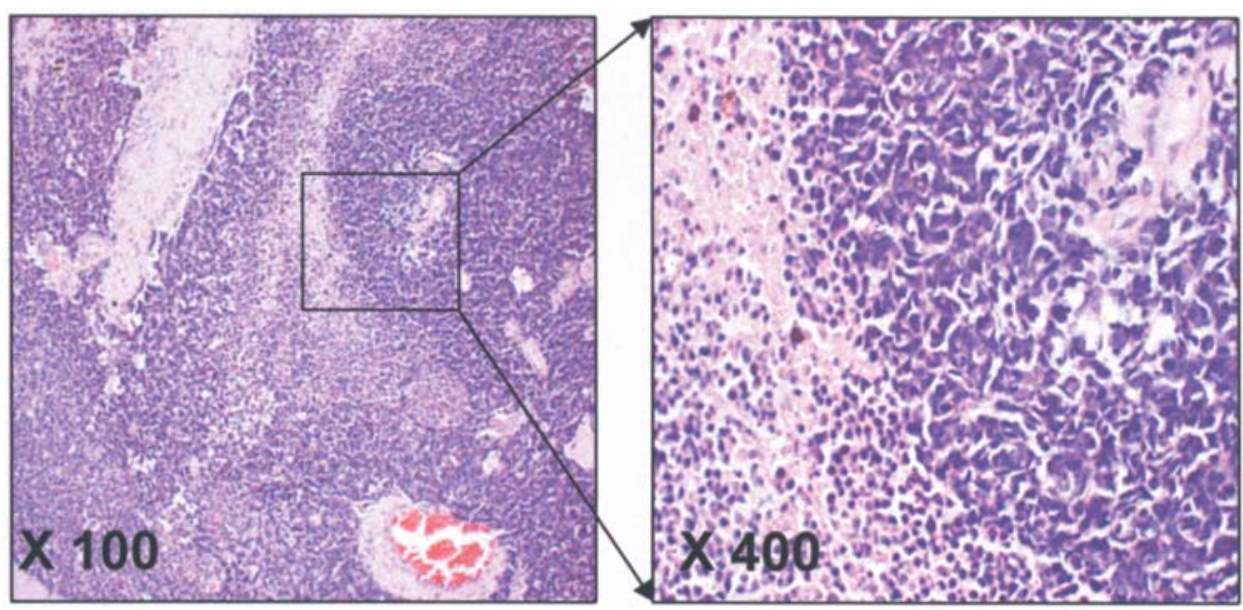

B

\section{Retinoic acid $(10 \mu \mathrm{M})$}

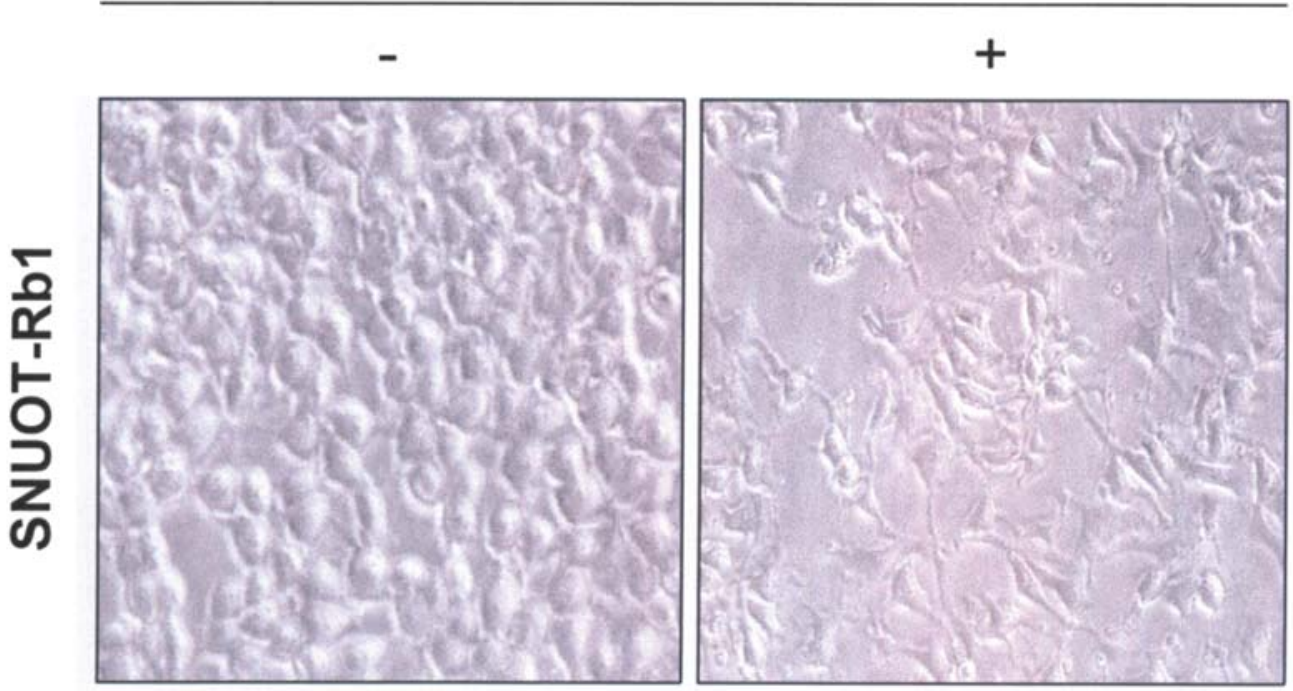

Figure 1. Histopathological features of the primary tumor and morphology of SNUOT-Rb1. Paraffin-embedded section of retinoblastoma tissue was stained with hematoxylin and eosin (A). SNUOT-Rb1 was isolated and then treated with $10 \mu \mathrm{M}$ RA for 10 days (B).

receptor $\alpha(\mathrm{RAR} \alpha)$ mRNA expression in both Y79 cells and SNUOT-Rb1 (Fig. 2A). Furthermore, the expression of GFAP and NSE were also detected through immunocytochemical staining (Fig. 2B) (11-13). The average population-doubling time of SNUOT-Rb1 was $24 \mathrm{~h}$, whereas that of Y79 was $33 \mathrm{~h}$ in suspension or $50 \mathrm{~h}$ in attached monolayer (Fig. 2C) $(8,9)$.

Tumor formation in vivo. Tumor formation was observed in all 30 nude mice intravitreally inoculated with $10^{7}$ cells of SNUOT-Rb1. Tumor development was checked by indirect ophthalmoscopic examination. All tumors reached maximum size between 15 and 20 days after intravitreal inoculation. Twenty-one days after inoculation, nude mice were sacrificed and enucleated for pathological examination (20 eyes) and tumor cell reculture (10 eyes). The tumors were composed of small, round cells with scanty cytoplasm and hyperchromatic nuclei surrounded by large areas of necrosis. Their appearance was identical to the primary tumor (Fig. 3A). The tumor cells were isolated and recultured in adherent growth, appearing morphologically identical to the SNUOTRb1 (Fig. 3B).

Cytogenetic analysis by $C G H$. We performed high-resolution matrix-CGH analysis on SNUOT-Rb1 and Y79. The chromosomal imbalances of Y79 were similar to those previously identified (14). SNUOT-Rb1 has significant chromosomal imbalances on chromosome 3, 9, 10, 11, 14, 16, 17, and 22. Comparing SNUOT-Rb1 to Y79, no significant chromosomal aberration was present on well-known sites of gene amplification in $\mathrm{Y} 79$, both the short arm of chromosome 2 and the long arm of chromosome 18 (Table I). N-myc amplification was not observed in SNUOT-Rb1. The significantly imbalanced chromosomal regions detected in SNUOT-Rb1 are listed in Table IB.

\section{Discussion}

The novel human retinoblastoma cell line, SNUOT-Rb1, was established from a 3-year old patient, who was diagnosed 
A

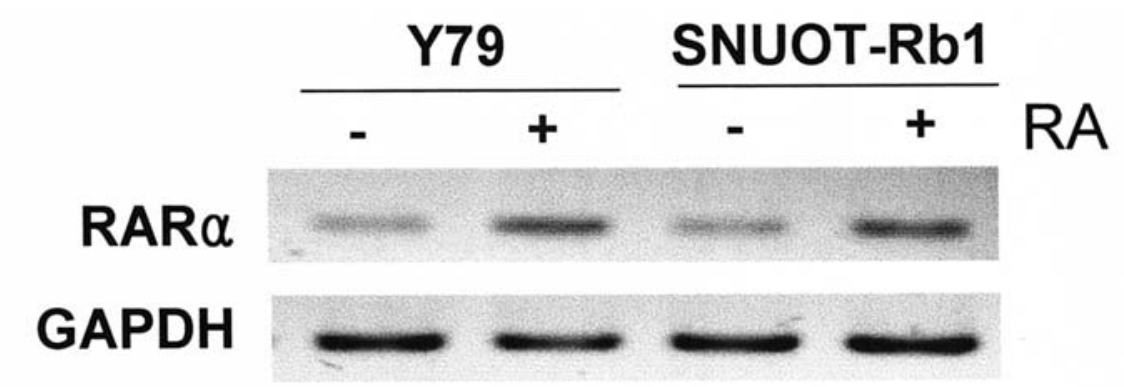

B

Control

GFAP

NSE
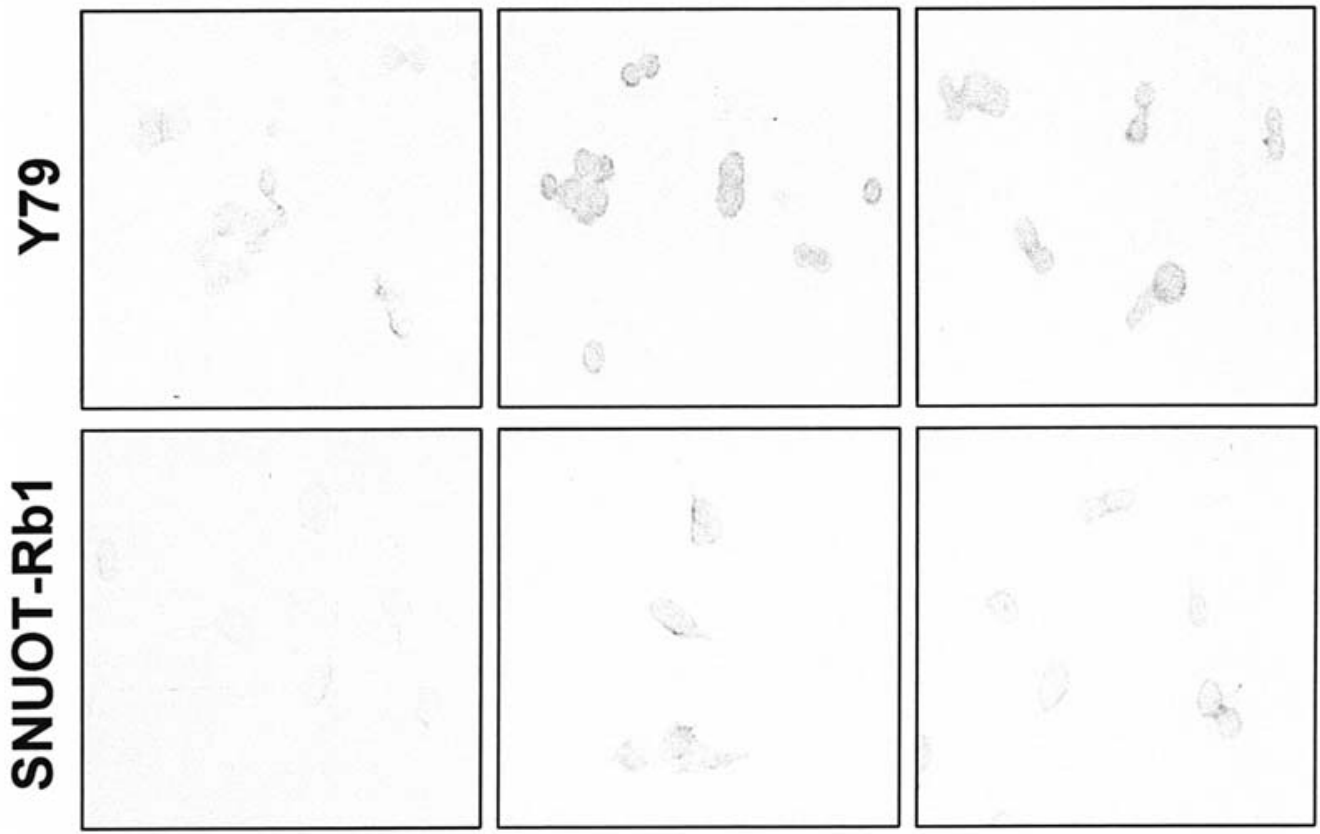

C

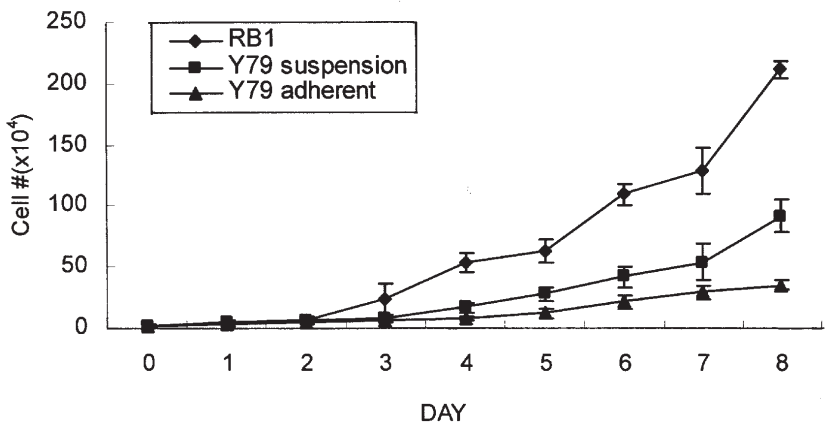

as having a primary retinoblastoma at Seoul National University Children's Hospital. The malignancy of this cell line was determined by measuring the doubling time of cells and in vivo tumorigenesis. The doubling time of SNUOT-Rb1 is shorter than Y79 in adherent or floating growth, which means active proliferation of SNUOT-Rb1 and reconfirmed in vivo tumorigenesis maximal growth between 15 to 20 days. SNUOT-Rb1 has morphological and biochemical characteristics common to previous human retinoblastoma cell lines: morphological features of fibroblast- or ganglion-
Figure 2. Induction differentiation of Y79 and SNUOT-Rb1 cell lines and in vitro growth characteristics. Cells were treated with $10 \mu \mathrm{M} \mathrm{RA}$ for 10 days and then RAR $\alpha$ mRNA expression was measured by RT-PCR (A), GFAP and NSE expression was detected by immunocytochemistry (B). The growth curves were plotted and the doubling times of the cell population were calculated from the exponential growth phase of the growth curves (C). like cells, and biochemical features of expression of GFAP and NSE (11-13). Furthermore, morphological and biochemical characteristics of SNUOT-Rb1 were constantly maintained in tumor cells isolated from tumors inoculated in the vitreal cavity of nude mice. In the present study, SNUOT-Rb1 was injected into the vitreal cavity of nude mice to examine tumor formation. This orthotopic implantation model mimics the pattern of local growth of retinoblastoma and may be an ideal model for determining the malignant potential of retinoblastoma cells (15). 
A

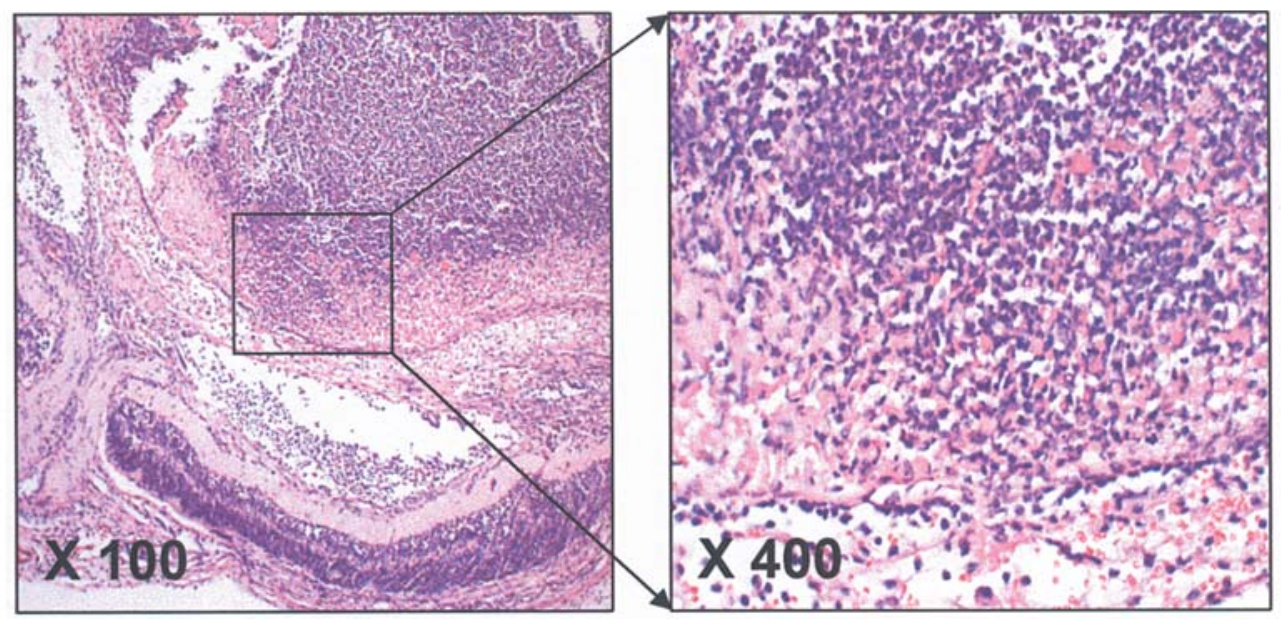

B

\section{Retinoic acid $(10 \mu \mathrm{M})$}

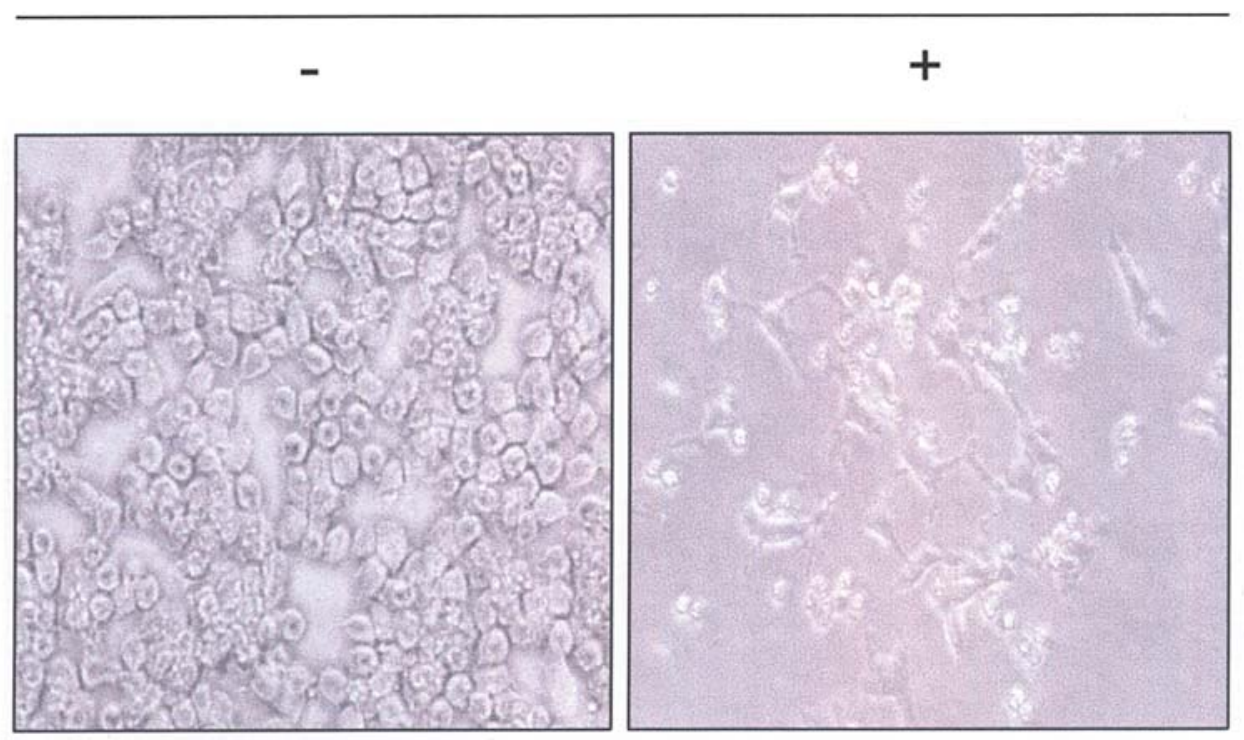

Figure 3. Analysis of tumorigenic potential of SNUOT-Rb1 in nude mice. SNUOT-Rb1 cells were injected into nude mice and the grown tumor was stained with hematoxylin and eosin (A). Tumor cells isolated from tumor tissue were treated with $10 \mu \mathrm{M}$ RA for 10 days (B).

Compared to Y79 or WERI-Rb1, SNUOT-Rb1 has an interesting, unique characteristic of growing in adherence, which is a great advantage over Y79 or WERI-Rb1 regarding easy manipulation for cell biologists to control gene expression. Therefore, even without cumbersome and sometimes expensive modifications to equipment, SNUOT-Rb1 may be suitable for use in a number of extremely important applications, including high-throughput drug screening formats, growth and expansion in roller bottles and expression cloning experiments.

In $\mathrm{CGH}$, we found that SNUOT-Rb1 has significant chromosomal imbalances on chromosome 3, 9, 10, 11, 14, 16, 17, and 22. Chromosomal imbalances of SNUOT-Rb1 were not identical to those of Y79 (14). The genetic composition and aberration of an established cell line may differ from the aberrant cell from which it originated. $\mathrm{N}$-myc amplification was not detected on SNUOT-Rb1, which could be an important prognostic factor presenting the proliferation activity of retinoblastoma cells. N-myc amplification could be a unique chromosomal aberration of Y79, whereas, n-myc amplification might not be common to retinoblastoma in general (14). CGH analysis of SNUOT-Rb1 identified a minimal $16 \mathrm{q}$ genomic loss that was previously described for primary retinoblastoma tumors (16). Loss at 16q23.2 and 16q24.2 was present in SNUOT-Rb1. This chromosomal loss of $16 \mathrm{q}$ may implicate the cadherin-11 gene or the cadherin-13 gene as a potential tumor suppressor gene in retinoblastoma (17), but a cluster of cadherin genes is located at $16 \mathrm{q} 22$. Detection of chromosomal loss by CGH has a resolution of $\sim 10$ to $20 \mathrm{Mbp}$ (18). Further studies for chromosomal aberrations of SNUOT-Rb1 remain necessary using retinoblastoma tumors.

In conclusion, SNUOT-Rb1 is a novel human retinoblastoma cell line, which has unique characteristics of adherent growth and chromosomal imbalances different from Y79 or WERI-RB1. Therefore, SNUOT-Rb1 should have many advantages for the study of biological and genetic characteristics. Also, an orthotopic implantation model using SNUOT$\mathrm{Rb} 1$ might be the most representative of retinoblastoma formation in the retina. 
Table I. CGH analysis: genomic imbalances detected by CGH in Y79 (A) and SNUOT-Rb1 (B).

\begin{tabular}{|c|c|c|c|c|c|}
\hline Chromosome no. & Locus name & Cytogenetic location & Mean ratio & Non-modal (p<x) & Gain/loss \\
\hline \multicolumn{6}{|l|}{ A } \\
\hline 1 & LAMC2 & $1 q 25-q 31$ & 1.35 & 0.0001 & ++ \\
\hline 1 & TGFB2 & $1 \mathrm{q} 41$ & 1.34 & 0.0002 & ++ \\
\hline 1 & WI-5663, WI-13414 & $1 q 21$ & 1.28 & 0.0005 & ++ \\
\hline 1 & AKT3 & $1 q 44$ & 1.30 & 0.001 & ++ \\
\hline 1 & PTGS2 (COX2) & 1q31.1 & 1.23 & 0.005 & ++ \\
\hline 1 & 1QTEL10 & $1 \mathrm{q}$ tel & 1.21 & 0.01 & ++ \\
\hline 2 & MYCN (n-myc) & $2 \mathrm{p} 24.1$ & 19.65 & 0.0001 & ++ \\
\hline 2 & $\mathrm{MSH} 2, \mathrm{KCNK} 12$ & $2 \mathrm{p} 22.3-2 \mathrm{p} 22.1$ & 1.38 & 0.0001 & ++ \\
\hline 2 & GNLY & 2p12-q11 & 1.47 & 0.0001 & ++ \\
\hline 2 & REL & 2p13-p12 & 1.33 & 0.0005 & ++ \\
\hline 5 & DHFR, MSH3 & $5 q 11.2-q 13.2$ & 1.21 & 0.01 & ++ \\
\hline 6 & PIM1 & 6p21.2 & 1.39 & 0.0001 & ++ \\
\hline 6 & 6PTEL48 & $6 \mathrm{p}$ tel & 1.27 & 0.001 & ++ \\
\hline 6 & CCND3 & $6 \mathrm{p} 21$ & 1.24 & 0.005 & ++ \\
\hline 8 & E2F5 & $8 p 22-q 21.3$ & 1.19 & 0.01 & ++ \\
\hline 15 & MAP2K5 & $15 q 23$ & 1.40 & 0.0001 & ++ \\
\hline 16 & CYLD & $16 q 12-q 13$ & 0.56 & 0.0001 & -- \\
\hline 17 & NME1 (NME23) & $17 q 21.3$ & 1.49 & 0.0001 & ++ \\
\hline 17 & RPS6KB1 (STK14A) & 17q23 & 1.46 & 0.0001 & ++ \\
\hline 17 & D17S 1670 & $17 q 23$ & 1.52 & 0.0001 & ++ \\
\hline 17 & TK1 & $17 \mathrm{q} 23.2-\mathrm{q} 25.3$ & 1.56 & 0.0001 & ++ \\
\hline 17 & AFM217YD10 & $17 q$ tel & 1.56 & 0.0001 & ++ \\
\hline 17 & TP53 (p53) & $17 \mathrm{p} 13.1$ & 1.32 & 0.0002 & ++ \\
\hline 17 & SHGC-103396 & $17 q$ tel & 1.35 & 0.0002 & ++ \\
\hline 17 & NF1 3' & $17 q 11.2$ & 1.24 & 0.005 & ++ \\
\hline 17 & BRCA1 & $17 q 21$ & 1.24 & 0.005 & ++ \\
\hline 17 & ERBB2 (HER-2) & $17 q 11.2-17 q 12$ & 1.26 & 0.005 & ++ \\
\hline 17 & PPARBP (PBP) & $17 q 12$ & 1.26 & 0.01 & ++ \\
\hline 18 & SHGC17327 & $18 \mathrm{p}$ tel & 1.71 & 0.0001 & ++ \\
\hline 18 & YES1 & 18p11.31-p11.21 & 1.46 & 0.0001 & ++ \\
\hline 18 & TYMS (TS) & $18 \mathrm{p} 11.32$ & 1.48 & 0.0001 & ++ \\
\hline 18 & LAMA3 & $18 q 11.2$ & 1.56 & 0.0001 & ++ \\
\hline 18 & FRA18A (D18S978) & $18 \mathrm{q} 12.3$ & 1.41 & 0.0001 & ++ \\
\hline 18 & 18QTEL11 & $18 \mathrm{q}$ tel & 1.65 & 0.0001 & ++ \\
\hline 18 & D18S552 & $18 \mathrm{p}$ tel & 1.31 & 0.0005 & ++ \\
\hline 18 & BCL2 3' & $18 \mathrm{q} 21.3$ & 1.29 & 0.002 & ++ \\
\hline 20 & 20QTEL14 & $20 q$ tel & 0.62 & 0.0001 & -- \\
\hline 21 & RUNX1 (AML1) & $21 \mathrm{q} 22.3$ & 1.37 & 0.0001 & ++ \\
\hline 21 & DYRK1A & $21 q 22$ & 1.41 & 0.0001 & ++ \\
\hline 21 & 21QTEL08 & $21 q$ tel & 1.47 & 0.0001 & ++ \\
\hline 21 & PCNT2 (KEN) & $21 q$ tel & 1.28 & 0.001 & ++ \\
\hline 21 & D21S341, D21S342 & $21 \mathrm{q} 22.3$ & 1.25 & 0.01 & ++ \\
\hline $\mathrm{X}$ & OCRL1 & $\mathrm{Xq} 25$ & 1.61 & 0.0001 & ++ \\
\hline \multicolumn{6}{|l|}{ B } \\
\hline 1 & D1S214 & 1p36.31 & 1.35 & 0.01 & ++ \\
\hline 1 & D1S1635 & $1 \mathrm{p} 36.22$ & 1.33 & 0.01 & ++ \\
\hline 1 & D1S199 & $1 \mathrm{p} 36.13$ & 1.33 & 0.01 & ++ \\
\hline 3 & RASSF1 & $3 p 21.3$ & 0.7 & 0.005 & -- \\
\hline
\end{tabular}


Table I. Continued.

\begin{tabular}{|c|c|c|c|c|c|}
\hline Chromosome no. & Locus name & Cytogenetic location & Mean ratio & Non-modal $(\mathrm{p}<\mathrm{x})$ & Gain/loss \\
\hline 3 & FHIT & $3 \mathrm{p} 14.2$ & 0.70 & 0.005 & -- \\
\hline 3 & $\mathrm{p} 44 \mathrm{~S} 10$ & $3 p 14.1$ & 0.69 & 0.005 & -- \\
\hline 9 & AF170276 & $9 \mathrm{p}$ tel & 0.60 & 0.0001 & -- \\
\hline 9 & D9S913 & $9 \mathrm{p}$ tel & 0.44 & 0.0001 & -- \\
\hline 9 & MTAP & $9 \mathrm{p} 21.3$ & 0.56 & 0.0001 & -- \\
\hline 9 & CDKN2A (P16), MTAP & 9p21 & 0.52 & 0.0001 & -- \\
\hline 10 & D10S167 & 10p11-10q11 & 0.71 & 0.005 & -- \\
\hline 10 & GATA3 & $10 \mathrm{p} 15$ & 0.72 & 0.01 & -- \\
\hline 10 & FGFR2 & $10 q 26$ & 0.71 & 0.01 & -- \\
\hline 11 & CCND1 & $11 \mathrm{q} 13$ & 1.59 & 0.0001 & ++ \\
\hline 11 & MLL & $11 q 23$ & 1.77 & 0.0001 & ++ \\
\hline 11 & GARP & $11 q 13.5-q 14$ & 1.59 & 0.0002 & ++ \\
\hline 11 & EMS1 & $11 \mathrm{q} 13$ & 1.52 & 0.0005 & ++ \\
\hline 11 & PAK1 & $11 q 13-q 14$ & 1.57 & 0.0005 & ++ \\
\hline 11 & RDX & 11q22.3 & 1.51 & 0.0005 & ++ \\
\hline 11 & INS & $11 \mathrm{p}$ tel & 0.64 & 0.001 & -- \\
\hline 11 & CDKN1C (p57) & $11 \mathrm{p} 15.5$ & 0.65 & 0.001 & -- \\
\hline 11 & FGF4, FGF3 & $11 q 13$ & 1.48 & 0.001 & ++ \\
\hline 11 & ATM & $11 \mathrm{q} 22.3$ & 1.43 & 0.002 & ++ \\
\hline 11 & WT1 & $11 \mathrm{p} 13$ & 0.71 & 0.005 & -- \\
\hline 11 & KAL1 & $11 \mathrm{p} 11.2$ & 0.69 & 0.005 & -- \\
\hline 14 & AKT1 & $14 q 32.32$ & 0.69 & 0.005 & -- \\
\hline 14 & TCL1A & $14 q 32.1$ & 0.70 & 0.01 & -- \\
\hline 16 & ABCC1 (MRP1) & $16 \mathrm{p} 13.1$ & 0.56 & 0.0001 & -- \\
\hline 16 & stSG30213 & $16 q$ tel & 0.64 & 0.0002 & -- \\
\hline 16 & 16QTEL013 & $16 q$ tel & 0.66 & 0.001 & -- \\
\hline 16 & CDH13 & $16 \mathrm{q} 24.2-\mathrm{q} 24.3$ & 0.67 & 0.002 & -- \\
\hline 16 & EMP2 & $16 \mathrm{p} 13.3$ & 0.70 & 0.005 & -- \\
\hline 16 & LZ16 & 16q24.2 & 0.71 & 0.005 & -- \\
\hline 16 & CYLD & $16 q 12-q 13$ & 0.72 & 0.01 & -- \\
\hline 16 & FRA16D & $16 \mathrm{q} 23.2$ & 0.72 & 0.01 & -- \\
\hline 17 & LLGL1 & $17 \mathrm{p} 12-17 \mathrm{p} 11.2$ & 0.66 & 0.001 & -- \\
\hline 17 & 282M15/SP6 & $17 \mathrm{p}$ tel & 0.66 & 0.002 & -- \\
\hline 17 & FLI, TOP3A & $17 \mathrm{p} 12-17 \mathrm{p} 11.2$ & 0.69 & 0.002 & -- \\
\hline 17 & Wl-14673 & $17 p$ tel & 0.72 & 0.01 & -- \\
\hline 19 & 129F16/SP6 & $19 \mathrm{p}$ tel & 0.71 & 0.01 & -- \\
\hline 19 & CCNE1 & $19 q 12$ & 0.73 & 0.01 & -- \\
\hline 22 & BCR & $22 q 11.23$ & 0.63 & 0.0005 & -- \\
\hline 22 & TBX1 & $22 q 11.23$ & 0.72 & 0.005 & -- \\
\hline 22 & GSCL & $22 q 11.21$ & 0.72 & 0.01 & -- \\
\hline
\end{tabular}

\section{Acknowledgements}

Thanks go to Digital Genomics Ltd. (Seoul, South Korea) for microarray-CGH analysis and Hyun Suk Jeong and Su Hee Jeong for technical help of experiments. This study was supported by a grant from the National R\&D program for cancer control, Ministry of Health and Welfare, Republic of Korea (05-20240-1).

\section{References}

1. Newsham IF, Hadjistilianou T and Cavenee WK: Retinoblastoma. In: The Genetic Basis of Human Cancer. 2nd edit. Vogelstein B and Kinzler KW (eds). McGraw-Hill, New York, pp357-386, 2002.

2. Gallie BL and Phillips RA: Retinoblastoma: a model of oncogenesis. Ophthalmology 91: 666-672, 1984.

3. Conway RM, Wheeler SM, Murray TG, Jockovich ME and O'Brien JM: Retinoblastoma: animal models. Ophthalmol Clin North Am 18: 25-39, 2005. 
4. Godbout R, Dryja TP, Squire JA, Gallie BL and Phillips RA: Somatic inactivation of genes on chromosome 13 is a common event in retinoblastoma. Nature 304: 451-453, 1983.

5. Gallie BL, Campbell C, Devlin H, Duckett A and Squire JA: Developmental basis of retinal-specific induction of cancer by RB mutation. Cancer Res 59: 1731-1735, 1999.

6. Lee EY, Chang CY, Hu N, et al: Mice deficient for Rb are nonviable and show defects in neurogenesis and hematopoiesis. Nature 359: 284-288, 1992.

7. Horsthemke B: Genetics and cytogenetics of retinoblastoma. Cancer Genet Cytogenet 63: 1-7, 1992

8. Reid TW, Albert DM, Rabson AS, et al: Characteristics of an established cell line of retinoblastoma. J Natl Cancer Inst 53: 347-360, 1974

9. McFall RC, Sery TW and Makadon M: Characterization of a new continuous cell line derived from a human retinoblastoma. Cancer Res 37: 1003-1010, 1977.

10. Li A, Zhu X and Craft CM: Retinoic acid upregulates cone arrestin expression in retinoblastoma cells through a cis element in the distal promoter region. Invest Ophthalmol Vis Sci 43: $1375-1383,2002$.

11. Messmer EP, Font RL, Kirkpatrick JB and Hopping W Immunohistochemical demonstration of neuronal and astrocytic differentiation in retinoblastoma. Ophthalmology 92: 167-173, 1985.
12. Xu KP, Liu SL and Ni C: Immunohistochemical evidence of neuronal and glial differentiation in retinoblastoma. Br J Ophthalmol 79: 771-776, 1995.

13. Perentes E, Herbort CP, Rubinstein LJ, et al: Immunohistochemical characterization of human retinoblastomas in situ with multiple markers. Am J Ophthalmol 103: 647-658, 1987.

14. Bie W, Squire JA, Fraser M, Paterson MC and Godbout R: Mitochondrial ATP synthase $\alpha$-subunit gene amplified in a retinoblastoma cell line maps to chromosome 18 . Genes Chromosomes Cancer 14: 63-67, 1995.

15. Chevez-Barrios P, Hurwitz MY, Louie K, et al: Metastatic and nonmetastatic models of retinoblastoma. Am J Pathol 157: 1405-1412, 2000.

16. Chen D, Gallie BL and Squire JA: Minimal regions of chromosomal imbalance in retinoblastoma detected by comparative genomic hybridization. Cancer Genet Cytogenet 129: 57-63, 2001.

17. Marchong MN, Chen D, Corson TW, et al: Minimal 16q genomic loss implicates cadherin-11 in retinoblastoma. Mol Cancer Res 2: 495-503, 2004.

18. Kallioniemi A, Kallioniemi OP, Sudar D, et al: Comparative genomic hybridization for molecular cytogenetic analysis of solid tumors. Science 258: 818-821, 1992. 